\title{
DIGITAL DIPLOMACY APPROACHED AS A SUBTYPE OF PUBLIC DIPLOMACY
}

\author{
Andreia-Mariana Pop ${ }^{1}$ \\ "Carol I" National Defence University
}

\begin{abstract}
As a subtype of new Public Diplomacy, Digital Diplomacy is considered one of the major trends of the twenty-first century in diplomatic communication and during the Covid-19 pandemic this aspect was reiterated. The importance of Digital Diplomacy is based on the usage of communication technologies, the internet and social media, which at the same time represent its base, for the strengthening of the diplomatic relations. Covid-19 has disrupted almost every aspect of life and diplomacy is no exception. Today, Digital Diplomacy has become a standard practice and we have to mention that it doesn't replace the traditional diplomacy, but complements it. In the context of the Covid-19 pandemic, for international actors was clear how important the exploitation of Digital Diplomacy benefits is.
\end{abstract}

Keywords: Digital Diplomacy; Public Diplomacy; Crisis Management; Social Media.

\section{INTRODUCTION}

Pandemics are atypical contexts characterized by outbreaks of infectious diseases affecting individuals and communities over a wide geographical area. With many "unknowns" as well as ebbs and flows, pandemics are non-linear and challenging.

Modern diplomacy is currently going through fundamental changes at an unprecedented rate. Technical developments, and mainly digitization, affect how the services and work of diplomats is understood; the public is now more sensitive to foreign policy issues and is searching for ways to influence diplomacy through social media and other platforms.

Technological innovations like the internet have given practitioners new ways of reaching out to foreign publics and have had wide reaching effects on international communication and thereby on Public Diplomacy. Developments and changes in communication behavior mainly due to the emergence of networked forms of technology influence the work of Public Diplomacy practitioners immensely. These changes and developments include a greater importance of public opinion, more global and intrusive media, globalization making it more desirable to protect cultural diversity, and increasing global transparency. Digital Diplomacy uses communication theologies, the internet and social media to strengthen diplomatic relations.

The role of the digital media in the world of diplomacy is critical. Before the Covid-19 spread, digital media almost inevitably meant social media. Covid-19 has created a scenario for countries around the world to seize the moment to pursue for.

The main purposes of this paper are: to explain the characteristics of Digital Diplomacy and to present the evolution of Digital Diplomacy during the Covid-19 pandemic.

The paper is divided into two chapters. The first one is about the characteristics of Digital Diplomacy. This chapter offers information on the definition of Digital Diplomacy and the main goals of Digital Diplomacy. The second chapter presents the evolution of Digital Diplomacy in the pandemic era.

${ }^{1}$ Corresponding author: popandreia@myunap.net 


\section{RESEARCH METHODOLOGY}

The current research interests focus on the impact of digital technology on the conduct of diplomacy, especially on the Public Diplomacy field. Due to the international Covid-19 crisis all states needed to adapt their Public Diplomacy strategy into a complex digital plan in order to keep a connection with their target audience.

For the realization of this article were used qualitative methods:

- Collection and selection of material (scientific journals, documents, sources from the internet, etc.);

- Applied methods (comparative, narrative, based theory, etc.).

\section{THE DEFINITION AND MAIN GOALS OF DIGITAL DIPLOMACY}

By the fact that diplomacy is now emerging as a social institution, Digital Diplomacy is now perceived as a subtype of Public Diplomacy and involves the use of a variety of digital platforms and tools of communication. (Vinod n.d.)

Diplomacy comes in many shapes and sizes. It is in under the guidance of presidents and prime ministers as well as lawyers, scientists, economists, aid workers, and of course, ambassadors. They presented the diversity of potential diplomatic actors, but also the coherence of what we might call the "diplomatic style" - the effort to increase power and influence through innovative partnerships and strategies.

Basically, the main goals of Digital Diplomacy are knowledge management, information, consular communications and response, disaster response, external resources and policy planning. To explain the evolution of Digital Diplomacy, must be restored to the effects of the technological revolutions of the nineteenth and twentieth centuries in diplomatic communication, appearing Public Diplomacy.

Public Diplomacy refers to processes in which countries seek to accomplish their foreign policy goals by communicating with foreign publics. It is also a tool for creating a positive climate amongst foreign populations in order to facilitate the acceptance of one's policies. Conceived in 1965 by Edmund Gullion, a US career diplomat, Public Diplomacy literally reaches beyond traditional diplomacy, aiming at the cultivation by governments of public opinion in other countries. (Public Diplomacy -Edmund Gullion n.d.)

The use of social media in Public Diplomacy activity created a new kind of collective memory that saves stories and events that would otherwise be forgotten quickly. This new collective memory could make Digital Diplomacy efforts more sustainable, as all the information will be available online even when a project is long terminated.

Digital Diplomacy was developed at the end of the twentieth century, but the concept of Digital Diplomacy has also been called eDiplomacy or cyber diplomacy. The first developments of eDiplomacy ("E" is the abbreviation of the word "electronic") belong to 1992 when at the Earth Summit in Rio de Janeiro for the first-time civil society e-mails were used for lobbying in the negotiations as well as at the same time in Malta, at the Mediterranean Academy of Diplomatic Studies, was founded the first unit for computer applications in diplomacy (Diplo 2014).

On the other hand, many diplomats have often considerate the Arab Spring as the origin of Digital Diplomacy. The use of digital media in diplomacy had begun earlier, but at the beginning of the Arab Spring it was estimated that on the internet were recruited most of the youths to Jihadi movements. Realizing the need to counter Al-Qaeda's recruitment tactics, and its online narrative, President Bush's Undersecretary for Pubic Diplomacy and Public Affairs launched Public Diplomacy 2.0. (Manor 2017)

Media coverage is almost instantaneous not only thanks to the media, but also through smart phones and social networks. As evidenced by the revolutions involving the Arab world in the spring of 2011, authoritarian states find it difficult to control the flow of information. (Manor 2017) Social media, like other forms of technology, are making societies much more democratic, but they are also offering them new tools of control in power. Therefore, Digital Diplomacy should be combined with smart power, which means maximum utilization of the benefits of digitization and empowering protection 
policies against various threats arising from communication technologies, the internet and social media because there is no escape from digitization.

The term Digital Diplomacy 2.0 has three main characteristics: The first one is the capacity of technology to facilitate the creation of relationships around social networks and on-line communities. The second characteristic is the related dependence of Public Diplomacy 2.0 on user-generated content from feedback and blog comments to complex user-generated items such as videos or mashups. The third characteristic is the underlying sense of the technology as being fundamentally about horizontally arranged networks of exchange rather than the vertically arrange networks of distribution down which information cascaded in the 1.0 era.

Hence, the new challenge facing diplomacy is to use the Internet and the social media as tools at the disposal of foreign action. "Diplomacy 3.0": the transition from digital communication to Digital Diplomacy. (Antonio Casado Rigalt 2017)

In the figure below we can observe how Digital Diplomacy is applied. A digital plan on Public Diplomacy is always targeting the government of the target state. The continuous lines are the main direction of the strategy and the dash lines refer to the primary message that may be edited or adapted to fit the target audience.

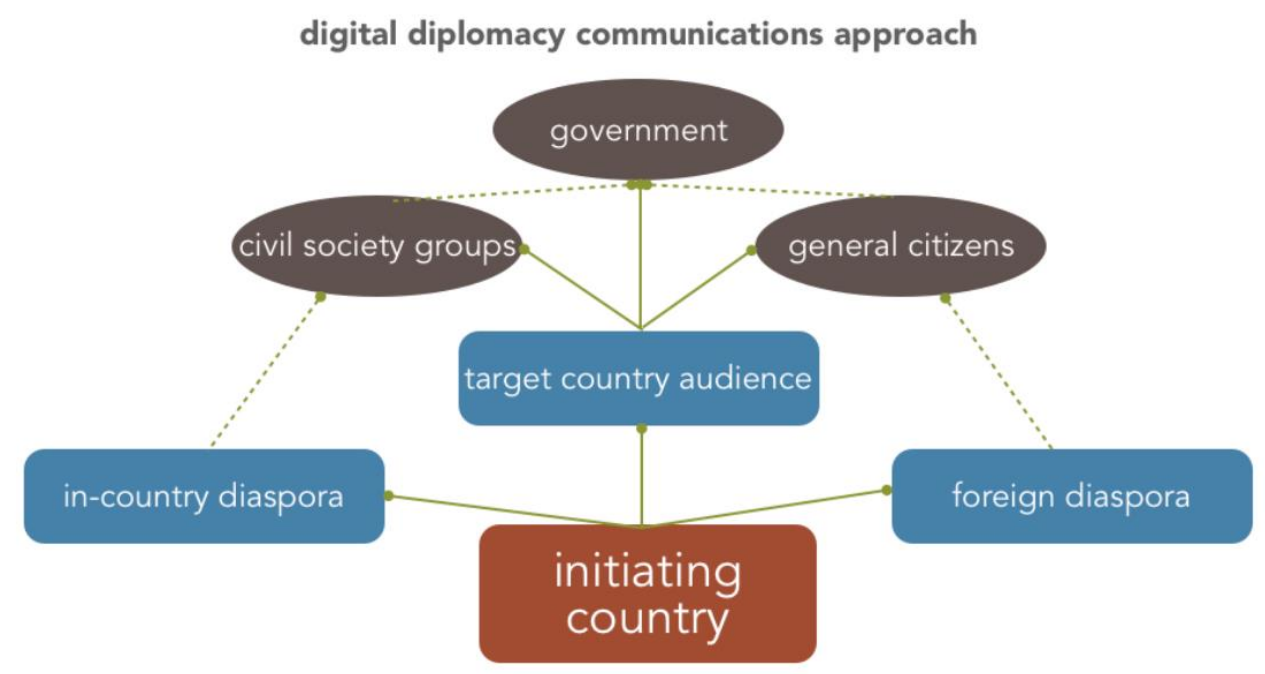

Figure 1. Digital Diplomacy Communications Approach

Source: https://envoycentre.wordpress.com/2014/01/22/what-is-digital-diplomacy/

Diplomats may use social media to keep track of events, collect information, and identify key influencers. They also have avenues for leverage that aren't limited to the conventional audience. They will assist with the consultation process, policy development, and concept sharing. There is still a lot of content on the internet that is of uncertain quality. (Rashica 2019 ) Because of the way social media operates, it has a massive influence, and it would be great to help as much as possible as the truth emerges. For the time being, the position and value of social media networks such as Twitter, Facebook, Instagram, and YouTube is increasingly increasing, with the latter being vital communication tools for many politicians and diplomats around the world.

The new networking technology have also had a major effect on harmful incidents. Terrorist and xenophobic organizations use them to rally and attract supporters. The social media movement is altering people's perceptions of the environment and how they communicate. (Stanzel 2018) It has not only made it easier for governments and diplomats to communicate with the media, but it has also increased public awareness of the consequences - both positive and negative - a Facebook comment, video, or image can have in a relatively short timeframe. Users of Digital Diplomacy must be trained and practiced on a regular basis, as well as integrate new digital technology as soon as possible. 
The adoption of Digital Diplomacy by foreign subjects, predominantly governments, is focused on a variety of priorities, with the latter being the most active. According to the researcher Viona Rashica, the main goals of digital diplomacy include a large category of aspects from Public Diplomacy and Consular communication to Policy planning and Disaster response (Rashica, The Benefits and Risks of Digital Diplomacy 2018):

Public Diplomacy: To maintain contact with audiences as they migrate online and to harness new communications tools to listen to and target important audiences with key messages and to influence major online influencers;

Information management: To help aggregate the overwhelming flow of information and to use this to better inform policy-making and to help anticipate and respond to emerging social and political movements;

Consular communications and response: To create direct, personal communications channels with citizens travelling overseas, with manageable communications in crisis situations;

Disaster response: To harness the power of connective technologies in disaster response situations;

External resources: Creating digital mechanisms to draw on and harness external expertise to advance national goals;

Policy planning: To allow for effective oversight, coordination and planning of international policy across government, in response to the internationalization of the bureaucracy.

The strategic use of digital platforms establishes the order on digital activities through the definition of measurable goals, target audiences, and parameters for evaluation. The goals decide the target audience, which in turn decides the platforms and methods to be used.

The threat of adversely manipulating data or hacking sensitive data is the greatest risk of the digital world. The Russian government's digital misinformation operations, which have reportedly tried to undermine political processes in Europe and the United States in recent years, provide credible evidence in this case. (Bjola 2018) More worryingly, how the digital medium operates makes it an easy target for use in propaganda. Due to the confirmation bias that online echo-chambers allow and perpetuate, misinformation spreads quicker, reaches deeper, becomes more emotionally charged, and, most significantly, becomes more resilient as a result of algorithmic content delivery and the circumvention of conventional media filters and opinion-formation gatekeepers. (Bjola, "Getting Digital Diplomacy right: what quantum theory can teach us about measuring impact." 2016)

Facebook was facing the harshest criticism of its history of privacy practices and how it treats user data, known as the "Cambridge Analytica Data Scandal". The analytical data firm that has worked with US President Donald Trump's electoral team and the Brexit winner campaign, and has taken millions of American voters data and has used them to build a powerful software program to predict and influence the US presidential election of 2016. Cambridge Analytica had access in informations of over 87 million Facebook users without their knowledge. (Cadwalladr 2018)

As mentioned, Digital Diplomacy does not replace traditional diplomacy, but it can strengthen the state's work in international relations quickly and more effectively. Today, it is an essential element for realizing foreign policy. Digital Diplomacy helps a lot in advancing its foreign policy goals, expanding international alignment, and affecting people who never set foot in any of the embassies of the world. (Adesina 2017)

Generally, Digital Diplomacy has four primary aspects: direct foreign engagement with a target country, domestic awareness of foreign policy, domestic Public Diplomacy and engagement of diaspora communities at home and abroad. (What Is Digital Diplomacy? 2014)

Last, but not least, the costs of using new technologies are falling rapidly as a result of continuous technology advancements. International practice shows that competent use of Digital Diplomacy tools can bring big dividends to those who invest in it. Moreover, Digital Diplomacy does not always require financial investments and this fact makes Digital Diplomacy more attractive to governments and embassies for spreading their work. 


\section{DIGITAL DIPLOMACY IN THE COVID ERA}

The global health crisis precipitated by Covid-19 has ushered in a new chapter in Public Diplomacy, as border closures, lockdowns, and social distancing become the norm across the globe. As nations struggle to contain Covid-19, in a pandemic fraught with life-and-death decisions and uncertainties about shifting economic, social, and political power.

Since the Covid-19 pandemic has changed or postponed most Public Diplomacy plans for 2020, both state and non-state actors have had to adapt their approach to fit into this new reality in which restrictions on travel and gatherings have resulted in events becoming less frequent and maintaining a country's public image during these turbulent times can be a challenging task.

The Covid-19 can be a compelling context for investigating the intersections of Public Diplomacy and Digital Diplomacy and also represents a unique opportunity to examine Public Diplomacy activities during crises situation. The Covid-19 outbreak challenged digital Public Diplomacy activities at least in two ways. First, diplomats faced a public health threat, rather than a political, economic or military one. Second, the Covid-19 virus spread among nations with unprecedented speed so diplomats response had to be direct and in real time.

Diplomatic practitioners looked at new forms of technologies as instruments of diplomacy, for example, digitized approaches of regulatory mechanisms, implementation of innovative digital technologies, and mobilizing digital tools. The pandemic has accelerated governments to adopt tools such as e-government portals and the developments of specific websites as their country's national Covid-19 platform to disseminate information the development of the crisis.

In order to maintain in a strong connection with the public diplomats must: remain engaged with the targeted audience and have a long-term plan to interact with them. Digital engagement strategies are not new to Public Diplomacy. However, with the rise of social distancing and temporary pausing of in-person programs, seeking out actionable ways to connect through Digital Diplomacy has become an urgent matter. (losifidis 2016)

Covid-19 was also a governance crisis, by default a Public Diplomacy crisis, and in this particular situation citizens around the world had judged a country regarding the time of response to the crisis and the efficiency of actions taken by the government.

Generally, the Digital Diplomacy is not impacted by crises unless any of the following three points happen, altogether or independently: prolonged crisis, high level of intensity, affects the country's identity and culture.

Normally, all crises affect the perception of countries for a specific period of time. Perceptions affected during a brief period do not substantiate a lasting change of image. (Consulting 2020) In order for this to happen, a crisis must affect or be related to one of the following areas: Public Governance (National government), Identity and Culture (People), History and Land.

The change in perceptions is predominantly related to Public Governance at $95 \%$. While only $5 \%$ is grouped into Identity and Culture. This crisis is not related to History and Land. (Consulting 2020)

The pandemic has tested diplomats capacity to offer timely and effective consular assistance, to protect the national image of their countries as the crisis escalated, and to counter the digital disinformation spread by an anxious public or by strategically minded actors.

The main challenges faced by diplomats during pandemic were related to:

- The improvement of the online platforms to offer the stability and security required in meetings;

- Interact with the public exclusive online;

- Create content that may reach a high engagement rate;

- Organizing social and cultural events, meetings or conferences online;

- Adapting the diplomatic protocol rules to the online environment.

Considering all of the above, for diplomats a quick knowledge of various events can be an advantage to national interest in many cases. Digital technologies are extremely useful for gathering and processing information regarding diplomatic activities as well as for fast communications in urgent 
situations. They enable governments to think about the consequences of events in different parts of the world and how they affect their country.

If crisis management perceptions are affecting the image of a county, emotions will generate results or impact the following dimensions of Public Diplomacy: mainly the target audience will have a different perception about the country and that may affect the impact of previous messages that were disseminated to influence governmental decision. Other domains that may be affected are Cultural Exchange, Investments, Exports, Tourism.

Countries that have and use a Digital Diplomacy strategy have proven to be more resilient. Those who work to manage their image and manage perceptions and reputation have more control over their national brand. Digital Diplomacy strategy should be a tool to provide answers in terms of behavior during a crisis.

\section{CONCLUSIONS}

To conclude, "Digital Diplomacy", "e-diplomacy" and "cyber-diplomacy" are all terms that describe the same reality: the advent of a new diplomacy adapted to the digital world, mainly Digital Diplomacy can be stated as using the Internet and new communications technologies (i.e. the social media) to help international diplomatic objectives.

While digital technologies have demonstrated clear potential for revolutionizing how diplomats conduct Public Diplomacy, deliver consular services, or manage crises, one should nevertheless be mindful of the fact that the core function of diplomacy that is, relationship building and management cannot be accomplished without close and sustained human contact.

Digital Diplomacy supports Public Diplomacy which is built over time through perception. This perception is generally built on Public Governance, economic status and Cultural and Historical heritage. In order to accomplish its foreign policy objectives a state must implement an efficient digital plan.

The innovation potential of Digital Diplomacy remains largely untapped, but in order to access it, it is important to understand what Digital Diplomacy can serve to and how it should be managed.

Lack of knowledge about the usage of digital technologies, the internet and social media can result with a lot of consequences, conflicts, even with discharges of positions. Digital Diplomacy users need to be very careful about what they publish, especially in social media, because a single word, comment, like or a picture can have many negative effects.

\section{REFERENCES}

Adesina, Olubukola S. 2017. "Foreign policy in an era of digital diplomacy". Cogent Social Sciences. URL: https://www.tandfonline.com/doi/full/10.1080/23311886.2017.1297175

Antonio Casado Rigalt, A. 2017. Diplomacy 3.0": from digital communication to digital diplomacy . June. Accessed March 01, 2021. http://www.exteriores.gob.es/Portal/es/SalaDePrensa/ Multimedia/Publicaciones/Documents/2017_\%20ANALISIS_9\%20ENG.pdf

Bjola, Corneliu. 2018. Digital Diplomacy: From Tactics To Strategy. Accessed February 20, 2021. https://www.americanacademy.de/digital-diplomacy-tactics-strategy/

"Getting digital diplomacy right: what quantum theory can teach us about measuring impact". 2016. "Global Affairs, 345-353.

Cadwalladr, C. \& Harrison, G., E. 2018. Revealed: 50 million Facebook profiles harvested for Cambridge Analytica in major data breach. Accessed March 01, 2021. https://www.theguardian.com/news/2018/mar/17/cambridge-analytica-facebook-influence-uselection

Consulting, Bloom. 2020. COVID-19 The Impact on Nation Brands. July. Accessed March 01, 2021. https://www.bloom-consulting.com/ 
Diplo. 2014. 20 years of e-diplomacy (1992-2012). 11 02. Accessed March 01, 2021. https://www.diplomacy.edu/e-diplomacy/20-years.

Iosifidis, Petros, Wheeler, Mark. 2016. Public Diplomacy 2.0 and the Social Media. Accessed March 01, 2021. https://www.researchgate.net/publication/303097870_Public_Diplomacy_20_ and_the_Social_Media

Manor, Ilan. 2017. The Revolution Has Been Tweeted. April 25. Accessed March 01, 2021. https://digdipblog.com/2017/04/25/the-revolution-has-been-tweeted/

n.d. Public Diplomacy-Edmund Gullion. Accessed March 01, 2021. https://publicdiplomacy. wikia.org/wiki/Edmund_Gullion

Rashica, Viona. 2019. "Digital diplomacy: aspects, approaches and practical use. "European Perspectives - International Scientific Journal on European Perspectives volume 10, number 1 (17) 21-39.

The Benefits and Risks of Digital Diplomacy. 2018. Accessed March 01, 2021. https://www.researchgate.net/publication/330572468_The_Benefits_and_Risks_of_Digital_Dipl omacy

Stanzel, Volker. 2018. New Realities in Foreign Affairs: Diplomacy in the 21st Century. November 11. Accessed March 01, 2021. https://www.swp-berlin.org/en/publication/new-realities-in-foreignaffairs-diplomacy-in-the-21st-century/

Vinod, M. J. 2020. Digital diplomacy, the new normal,. July 26. Accessed March 01, 2021. https://www.deccanherald.com/opinion/digital-diplomacy-the-new-normal-866031.html

What Is Digital Diplomacy? 2014. Accessed March 2021. https://envoycentre. wordpress.com/2014/01/22/what-is-digital-diplomacy/ accessed on 20.02.2021 